\title{
Analysis of rural landscape pattern based on GIS in Yanqing, Beijing Zhao Qun ${ }^{1,2,3, a}$, Ma XiaoYan ${ }^{1,2,3, b,{ }^{*}}$, Hu ZhuoWei ${ }^{4, c}$ \\ ${ }^{1}$ Department of landscape architecture, Beijing University of Agriculture, Peking,Beijing 102206,China; \\ ${ }^{2}$ Beijing Rural Landscape Planning and Design Engineering Technology Center, Peking ,Beijing 102206,China; \\ ${ }^{3}$ Beijing Laboratory of Urban and Rural Ecological Environment, Peking ,Beijing 100083,China. \\ ${ }^{4}$ College of resources and environment and tourism, Capital Normal University \\ aqun_zhao@sina.com, ${ }^{b}$ mxyfan@163.com, chuzhuowei@mail.cnu.edu.cn
}

Keywords: GIS, rural, landscape pattern.

\begin{abstract}
In recent years, as the process of urbanization in china become fast, the new rural construction has a great impact on the original rural landscape pattern and appearance all over the country.How to protect the rural landscape in the new rural construction is the most concern of scholars.
\end{abstract}

\section{Introduction}

In the suburbs of Beijing City, rural areas are in the process of transforming from traditional agricultural landscape to modern agricultural landscape, and the rural landscape construction is facing a new opportunity. Such as, rural natural landscape and cultural landscape, from the suburbs to the outer suburbs, and Tazono Kanhikaru, orchard, forest tourism, "peasant music", folk culture, rural tourism develop rapidly. This is not only an effective way to promote the adjustment of local rural industrial structure, economic development and farmers to get rich, but also on the outskirts of the city of rural development has a strong impact.

Therefore, the research and analysis of landscape pattern of Yanqing Sihai Town, can provide reference for the new rural development and planning.

The forest resources of Sihai Town are abundant, the vegetation is lush, the forest cover rate is $79.42 \%$. The average temperature of Sihai Town is 4 degrees, annual rainfall is $700-550 \mathrm{~mm}$.Fresh air, pleasant climate, it is a place for summer holidays and leisure tourism.

\section{Image Data Processing}

Image data include 2004 SPOT 5 and 2010 GeoEye 1 satellite remote sensing image data, 2005 Landse data, DEM data, Contour distribution data and national basic geographic data (including road, traffic, water system, residents, etc.) .

Based on 10 m spatial resolution DEM data,through selecting some ground control points in the image,using the digital elevation model(DEM), correction of tilt correction and projection correction carried on to the image. Sampling the image into a normal shot. Mosaic multiple image into one.Through color balance, in a certain range of cutting out of the image is a positive image.

Through image fusion, ortho rectification, image registration and image mosaic, Image preprocessing is done. Through setting points, lines, and planes, the vector of the image is completed. Choose a reasonable color scheme, according to the method of visual interpretation, the distribution map of land use types was obtained by correlation analysis.

At last field survey and precision verification must be done. According to the distribution of sampling points, design sampling route, Land use types recorded at sampling points, through GPS positioning, according to field survey data on land use types verificate accuracy.According to land use types, Landscape is classificated . 


\section{Landscape Index Calculation}

Using FRAGSTATS 4.2 software, the main elements of rural landscape types is calculated.It is including CA,PLAND,LPI,LSI,PLADJ.

Table1 The numerical value of landscape elements in Sihai

(2004, 2010)

\begin{tabular}{|c|l|l|l|l|l|l|l|l|l|}
\hline Index & Year & $\begin{array}{c}\text { Cultivated } \\
\text { land } \\
\text { landscappe }\end{array}$ & $\begin{array}{c}\text { Garden } \\
\text { landscape }\end{array}$ & $\begin{array}{l}\text { Woodland } \\
\text { landscape }\end{array}$ & $\begin{array}{l}\text { Grassland } \\
\text { landscape }\end{array}$ & $\begin{array}{c}\text { Water } \\
\text { landscape }\end{array}$ & $\begin{array}{l}\text { Settlement } \\
\text { landscape }\end{array}$ & $\begin{array}{c}\text { Road } \\
\text { landscape }\end{array}$ & $\begin{array}{c}\text { Unused land } \\
\text { landscape }\end{array}$ \\
\hline CA & 2004 & 1456.1848 & 1.5834 & 7626.0545 & 654.7138 & 108.4825 & 161.3766 & 78.3074 & 34.3643 \\
\cline { 2 - 10 } & 2010 & 1451.8519 & 48.0239 & 7428.0636 & 797.9613 & 95.2861 & 165.1633 & 115.6721 & 19.7598 \\
\hline PLAND & 2004 & 14.3877 & 0.0156 & 75.3483 & 6.4688 & 1.0718 & 1.5945 & 0.7737 & 0.3395 \\
\cline { 2 - 10 } & 2010 & 14.3438 & 0.4745 & 73.3869 & 7.8836 & 0.9414 & 1.6318 & 1.1428 & 0.1952 \\
\hline LPI & 2004 & 1.7743 & 0.0051 & 47.1919 & 1.0718 & 0.1765 & 0.6054 & 0.4818 & 0.1074 \\
\cline { 2 - 10 } & 2010 & 1.7374 & 0.1924 & 19.5036 & 1.2588 & 0.1641 & 0.6053 & 0.8358 & 0.0245 \\
\hline LSI & 2004 & 24.5051 & 2.5952 & 11.4122 & 13.7247 & 12.6761 & 21.4136 & 54.0305 & 8.26 \\
\cline { 2 - 10 } & 2010 & 24.5136 & 6.1414 & 12.0738 & 15.6715 & 13.5346 & 22.7764 & 54.027 & 10.4427 \\
\hline PLADJ & 2004 & 99.3578 & 97.9348 & 99.8693 & 99.4636 & 98.7824 & 98.3141 & 93.8937 & 98.5903 \\
\cline { 2 - 9 } & 2010 & 99.3566 & 99.1138 & 99.8599 & 99.4452 & 98.613 & 98.2273 & 94.9743 & 97.6483 \\
\hline
\end{tabular}

Area analysis of landscape element type

From 2004-2010, the landscape, road landscape and grassland landscape increased significantly, Woodland landscape and water landscape decreased slightly,Not using the landscape significantly decreased.In all landscape types, forest landscape has always been in the dominant position.

\section{Analysis of shape features of landscape elements}

In 2004 and 2010, the largest of LSI is the road landscape.The shape of the road landscape is the most complex.Due to the continuous construction of roads, the road landscape is also the largest interference intensity.Next is the cultivated land landscape; the shape is relatively simple, the low level of disturbance is the garden landscape.

\section{Analysis on the aggregation and distribution of landscape elements}

In 2004 and 2010, the minimum PLADJ value is the road landscape, the largest is the forest landscape, the larger is the grassland landscape and farmland landscape.It showed that the forest landscape connectivity, centralized distribution, high degree of aggregation. The grassland landscape and farmland landscape is connectivity, distribution is relatively concentrated, high aggregation degree. The road landscape is poor connectivity, mainly composed of small patches.

\section{Summary}

Through the FRAGSTATS 4.2, Sihai town in Yanqing rural landscape pattern index, the patch degree, the degree of spread, the Shannon diversity index, the Shannon index, the degree of polymerization index value are computed. 
Table2 Regional landscape pattern index of Sihai (2004、2010)

\begin{tabular}{lllll}
\hline YEAR & COHESION & CONTAG & SHDI & SHEI \\
\hline 2004 & 99.9587 & 79.2064 & 0.8422 & 0.405 \\
2010 & 99.9383 & 77.6302 & 0.9056 & 0.4355 \\
\hline
\end{tabular}

\section{Landscape connectivity analysis}

In 2004 and 2010, the landscape types of the COHESION values remained stable and slightly decreased.In each period, the patch of the forest landscape was higher, the landscape connectivity was better, and it has a large proportion in the landscape,

\section{Landscape equilibrium analysis}

In 2004 and 2010, the CONTAG index values were 79.2064 and 77.6302, respectively, and the spatial distribution of the landscape types in 2010 and 2004 was the general trend of Yu Junheng, but a little discrete.

\section{Landscape diversity analysis}

2004 and 2010 SHDI were 0.8422 and 0.9056 , respectively, SHEI were 0.405 and 0.4355 , SHDI and SHEI were increased. The diversity of the study area is basically maintained, the distribution of the landscape types is basically uniform, and the number of landscape patches is small.However, the degree of fragmentation of the landscape has a rising trend, the degree of landscape heterogeneity increased slightly.

\section{Acknowledgement}

Thanks to the support of two projects.

1.Research base construction project:The application of $3 \mathrm{~S}$ technology in the planning and construction of the Science Park of BeiJing Agricultural University,Project code:PXM2015_014207_000010

2.Beijing laboratory construction of urban and rural ecological environment project, Project code:PXM2015_014207_000014

\section{References}

[1]S.Hattori,K.Akimoto,C.Fraser,H.Imoto.Automated procedures with coded targets in industuial vision metrology. Photo grammetric engineering and remote sensing [J],2002.68(5),PP441-446.

[2]Wu Lun, Zhang Jing, Liu Yu. Principles and Methods of Geographic Information System[M]. Beijing: Science Press, 2002. (in Chinese)

[3]Chai Hejun. The rock mass structure model and engineering application research of Xiluodu hydroelectric power station of Jinsha river[D].Chengdu: Chengdu University of Technology, 1999. (in Chinese)

[4]WuJianGuo.Landscape ecology: pattern, process, scale and grade [M].Beijing: Higher Education Press,2000.

[5]CCGIS V4.0 Enterprise Edition Description[D].GeoStar Communication, 2002, 39, unpublished. (in Chinese)

[6]LiuBinY. Modern landscape planning and design[M].Nanjing:Southeast University press, 1999.

[7]FuBoJie,etc.Principle and application of landscape ecology[M].Beijing:Science Press,2001.

[8]XuHui,WangJiaJi.Theory and application of landscape ecology[M].Beijing: Environmental Science Press, 1993.

[9]ZhaoYi, LiYueHui.Practical landscape ecology[M].Beijing:Science Press,2001. 
[10]YuanFei.Application of GIS in urban landscape planning and design[D]. Northwest Agriculture and Forestry University,2012. 